\title{
Intraoperative completion studies in carotid endarterectomy: systematic review and meta-analysis of techniques and outcomes
}

\author{
Christoph Knappich ${ }^{1}$, Thomas Lang ${ }^{1}$, Pavlos Tsantilas ${ }^{1}$, Sofie Schmid ${ }^{1}$, Michael Kallmayer ${ }^{1}$, \\ Bernhard Haller ${ }^{2}$, Hans-Henning Eckstein ${ }^{1}$ \\ ${ }^{1}$ Department for Vascular and Endovascular Surgery, Klinikum rechts der Isar, Technical University of Munich, Munich, Germany; ${ }^{2}$ Institute of \\ Medical Informatics, Statistics and Epidemiology, Klinikum rechts der Isar, Technical University of Munich, Munich, Germany \\ Contributions: (I) Conception and design: C Knappich, HH Eckstein; (II) Administrative support: P Tsantilas, M Kallmayer; (III) Provision of study \\ materials or patients: C Knappich, S Schmid; (IV) Collection and assembly of data: C Knappich, S Schmid; (V) Data analysis and interpretation: T \\ Lang, B Haller, C Knappich; (VI) Manuscript writing: All authors; (VII) Final approval of manuscript: All authors. \\ Correspondence to: Univ.-Prof. Dr. med. Hans-Henning Eckstein, MD, PhD. Department for Vascular and Endovascular Surgery, Klinikum rechts der \\ Isar, Technical University of Munich, Ismaninger Str. 22, 81675 Munich, Germany. Email: gefaesschirurgie@mri.tum.de.
}

Background: Declining perioperative stroke and death rates over the past 3 decades have been paralleled by an increasing use of intraoperative completion studies (ICS) following carotid endarterectomy (CEA). Techniques applied include angiography, intraoperative duplex ultrasound (IDUS), flowmetry, and angioscopy. This systematic review and meta-analysis is aiming on providing an overview of techniques and corresponding outcomes.

Methods: A PubMed based systematic literature review comprising the years 1980 through 2020 was performed using predefined keywords to identify articles on different ICS techniques. Pooled analyses and meta-analyses estimating risk ratios (RR) and 95\% confidence intervals (CI) were performed to compare outcomes of different ICS modes to nonapplication of any ICS. $\mathrm{I}^{2}$ values were assessed to quantify study heterogeneities.

Results: Identification of 34 studies including patients undergoing CEA with angiography $(\mathrm{n}=53,218)$, IDUS $(n=20,030)$, flowmetry $(n=16,812)$, and angioscopy $(n=2,291)$. Corresponding rates of perioperative stroke were $1.5 \%, 1.8 \%, 3.6 \%$, and $1.5 \%$, perioperative stroke or death occurred in $1.7 \%, 1.9 \%, 2.2 \%$, and $2.0 \%$. Intraoperative surgical revision rates were $6.2 \%, 5.9 \%$, and $7.9 \%$ after CEA with angiography, IDUS, and angioscopy, respectively. Compared to nonapplication of any ICS, the pooled analysis revealed angiography to be significantly associated with lower rates of stroke (RR 0.47; 95\% CI, 0.36-0.62; P<0.0001) and stroke or death (RR 0.76; 95\% CI, 0.70-0.83; P<0.0001). IDUS was significantly associated with lower rates of stroke (RR 0.56; 95\% CI, 0.43-0.73; P<0.0001) and stroke or death (RR 0.83; 95\% CI, 0.74-0.93; $\mathrm{P}=0.0018$ ), whereas angioscopy showed a significant association with a lower stroke rate (RR 0.48; 95\% CI, 0.033-0.68; $\mathrm{P}=0.0001$ ), but no effect on the combined stroke or death rate. Angioscopy was associated with a higher intraoperative revision rate compared to angiography (RR 1.29; 95\% CI, 1.07-1.54; $\mathrm{P}=0.006$ ). The meta-analyses confirmed lower perioperative stroke or death rates for angiography (RR 0.83; 95\% CI, 0.760.91) and IDUS (RR 0.86; 95\% CI, 0.76-0.98) compared to non-application of any ICS, whereas flowmetry showed no significant association.

Conclusions: This study represents the first systematic literature review and meta-analysis on usage of ICSs in CEA. Data strongly indicate a significant beneficial effect of angiography, IDUS, and angioscopy on perioperative CEA outcomes. Any carotid surgeon should consider implementation of ICSs in his routine armamentarium.

Keywords: Angiography; angioscopy; carotid endarterectomy (CEA); flowmetry; ultrasound; quality control

Submitted Mar 28, 2020. Accepted for publication Oct 16, 2020.

doi: 10.21037/atm-20-2931

View this article at: http://dx.doi.org/10.21037/atm-20-2931 


\section{Introduction}

Carotid endarterectomy (CEA) has been established as the treatment of choice for patients with a 50-99\% symptomatic stenosis of the extracranial portion of the internal carotid artery (ICA). In asymptomatic patients, CEA should be considered if the degree of stenosis exceeds $60 \%(1)$.

Decreasing perioperative stroke and death rates over the past 3 decades $(2,3)$ have been paralleled by an increasing use of intraoperative completion studies (ICS) following CEA (German statutory quality assurance database: $44.5 \%$ in 2003 vs. $68.3 \%$ in 2015 ) (4), suggesting a potential association.

Although there is a multitude of nonrandomized and retrospective series, which in part indicate ICSs to be beneficial, there still is a lack of prospective randomized data.

Due to this shortage of confirmatory trials, national and international carotid guideline recommendations disregarded ICSs for a long time (5-9).

While the "2017 Clinical Practice Guidelines of the European Society for Vascular Surgery (ESVS) on management of atherosclerotic carotid and vertebral artery disease" for the first time mentioned that targeted quality control strategies may reduce perioperative stroke or death (1), the recently published German-Austrian guidelines on carotid artery disease advanced to recommending that angiography or intraoperative duplex ultrasound (IDUS) should be used in CEA (10).

Techniques used as ICSs include intraoperative angiography, IDUS, flowmetry, and angioscopy. The present systematic review and meta-analysis was conducted to give an overview on these methods with their adherent strengths and drawbacks, and to compare the clinical outcomes of patients undergoing CEA with different ICSs to those treated without any ICS, respectively. We present the following article in accordance with the Preferred Reporting Items for Systematic Reviews and MetaAnalyses (PRISMA) checklist (available at http://dx.doi. org/10.21037/atm-20-2931).

\section{Overview on different ICS techniques}

The simplest way to control the result after CEA is digital palpation of the reconstructed artery. The presence or absence of a pulse indicates patency or occlusion of the blood vessel, respectively. Although the character of a pulse or the presence of a thrill can suggest possible pathologies, this measure is not accurate and documentation for forensic reasons, which has been gaining more importance over the years, is not feasible.

According to the German statutory quality assurance database, some form of ICS during elective CEA is applied in $67 \%$ of cases. Performed in $36 \%$, angiography is the technique employed most commonly followed by IDUS and flowmetry (13\% each) (11).

\section{Angiography}

An angiographic completion study can be performed easily and in a standardized manner.

After reconstruction of the carotid bifurcation, the common carotid artery is punctured retrogradely. For better opacification of the ICA and its intracranial branches it is advisable to execute an angiogram with the external carotid artery clamped. To assess both branches of the carotid bifurcation, the subsequent angiogram is done with the external carotid artery unclamped. Please see Figure $1 A, B, C$ for examples of angiographic images after CEA.

A major strength of this technique is the wide availability and feasibility with little expenditure of extra operating time. The technique is relatively independent from the applicator, nevertheless interpretation can be challenging and there are no officially recognized interpretation criteria to guide decision-making for or against intraoperative revision.

Contraindications are limited to severe renal disease and allergy to iodine containing contrast media. Although utilized frequently in patients with renal disease to prevent deterioration of kidney function, a benefit of periinterventional administration of sodium saline, sodium bicarbonate, and acetylcysteine is not proven $(12,13)$. Prophylactic pretreatment with $\mathrm{H} 1$ and $\mathrm{H} 2$ blockers, and steroids can be used in patients with previous mild allergic reaction to contrast media. Although gadolinium-based contrast agents can serve as alternative to iodinated contrast media in the previously mentioned patient groups, its usage comes along with reduced imaging quality.

Carotid angiography has itself been demonstrated to be associated with neurologic complications (14). In very rare cases, the arterial needle puncture may cause dissection (Figure 1C) or dislodgment of atheroma. Furthermore, angiography is connected with a certain radiation exposure for patients and operating personnel.

\section{IDUS}

After reconstruction, an imaging probe is placed directly on 

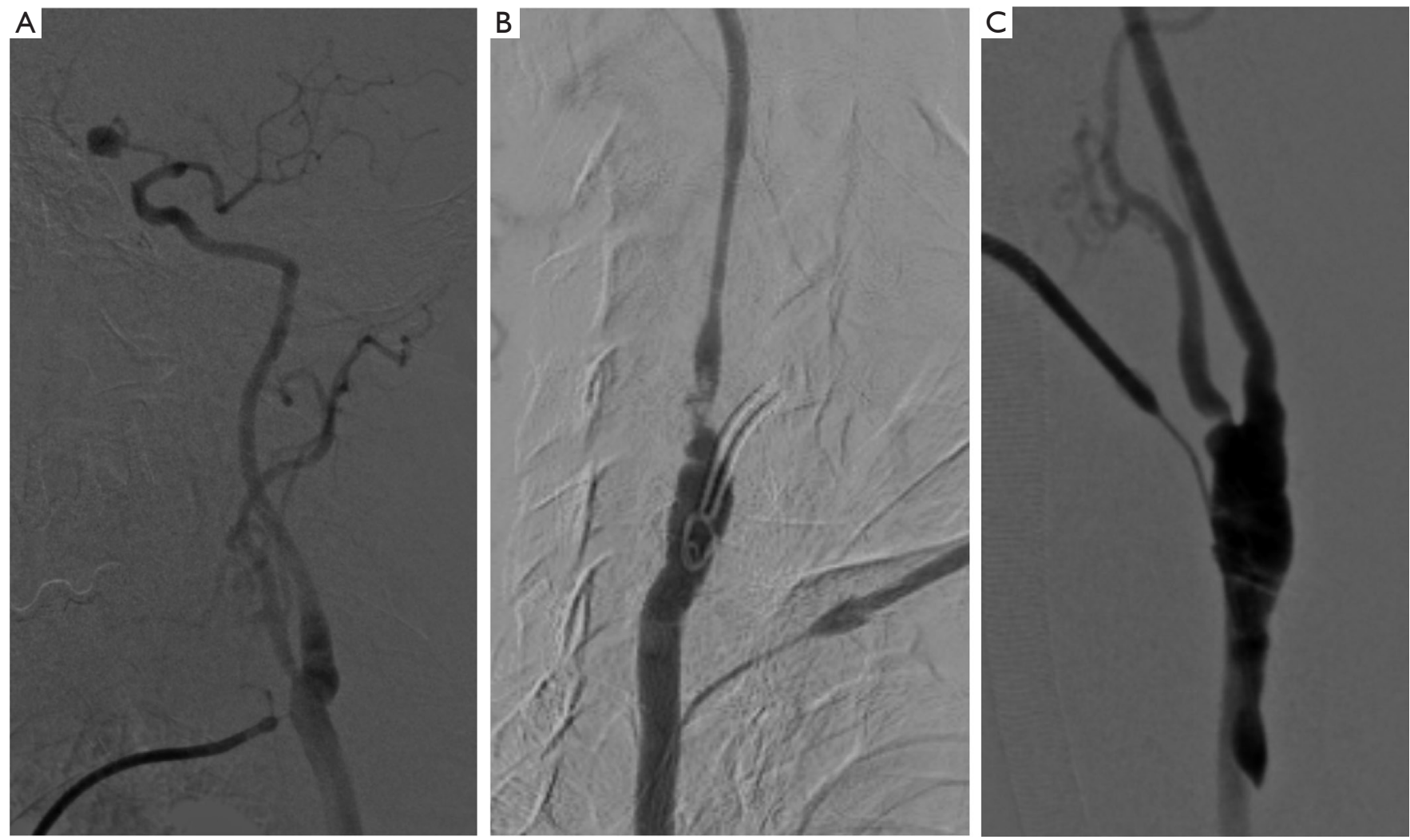

Figure 1 Intraoperative angiography. Intraoperative angiography of the carotid bifurcation with visualization of the intracranial ICA showing a concomitant aneurysm of the anterior communicating artery (A), showing a luminal thrombus at the origin of the ICA with the external carotid artery clamped (B), and demonstrating an accidental dissection of the common carotid artery caused by cannula (C). ICA, internal carotid artery.

the carotid artery (Figure $2 A$ ).

With frequencies up to $18 \mathrm{MHz}$, the probes have a penetration depth of about $5 \mathrm{~mm}$ with a high resolution. Ultrasound machines typically support B-mode, duplex and pulsatile wave doppler.

It is advisable the investigation to follow a standardized workflow. As proposed by Ascher et al., a transverse B-mode scan of the carotid bifurcation is followed by longitudinal scans to reveal morphological issues (15). Longitudinal scans should involve the proximal and distal intima step, as especially the latter one is at risk to be uplifted by the blood stream (Figure 2B).

Different interpretation criteria for morphologic and hemodynamic defects were published in the literature. Regarding hemodynamic criteria, a peak systolic velocity (PSV) of less than $150 \mathrm{~cm} / \mathrm{s}$ is usually interpreted as physiological $(16,17)$. A velocity ratio $(\mathrm{Vr})$, which is defined as the ratio of PSVs in the ICA and the common carotid artery (CCA), below 2 also is interpreted as normal (16). A PSV exceeding $150 \mathrm{~cm} / \mathrm{s}(16,17)$ as well as a $\mathrm{Vr}$ of more than 2 (16) indicates a moderate stenosis. A severe stenosis is suggested, if the PSV exceeds $300 \mathrm{~cm} / \mathrm{s}$ or the $\mathrm{Vr}$ amounts to more than 3.5 (16).

Regarding morphologic criteria, a lesion is considered relevant, if the residual narrowing exceeds $30 \%$. Furthermore, mobile intima flaps (Figure 2B,C) are considered relevant if larger than $2 \mathrm{~mm}$ in the ICA $(15,18,19)$ or larger than $3 \mathrm{~mm}(15)$ in the CCA.

\section{Flowmetry}

There exist different methods to detect flow volumes, including doppler flowmetry and transit time flowmetry (TTFM).

After CEA, the C-shaped flowmetry probe is placed on the CCA to measure the whole carotid flow. Clamping one of both, ICA and ECA briefly, can give an estimate on 

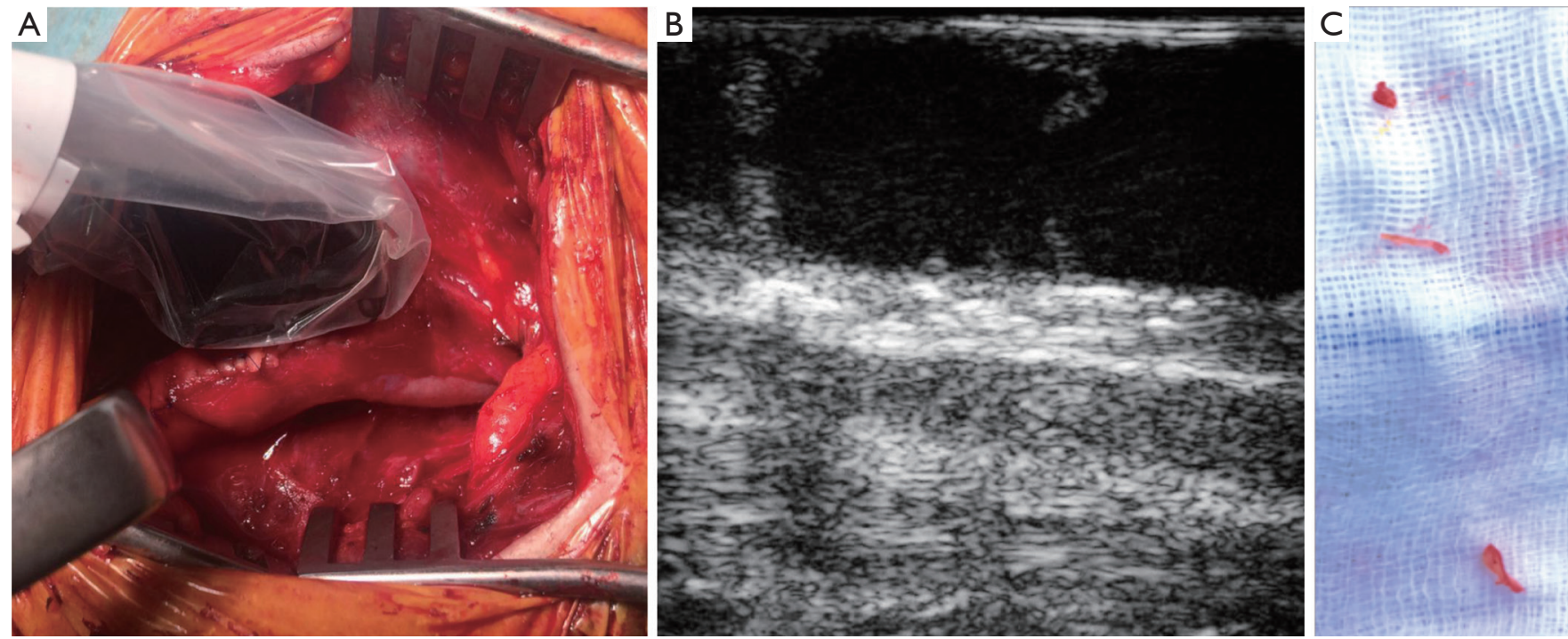

Figure 2 IDUS. Intraoperative setup with the ultrasound probe placed on the carotid artery (A). B-mode ultrasound image (blood flow from right to left) demonstrating various residual intima flaps within the internal carotid artery after carotid endarterectomy (B). Those were confirmed and resected during surgical revision (C). IDUS, intraoperative duplex ultrasound.

the flow volume of the other branch. Alternatively, smaller probes can be used to measure ICA and ECA flow directly.

In addition, the pulsatility index (PI) can be recorded, which is expressed as the ratio of the flow volume amplitude and mean flow volume, and serves as an estimate for the peripheral resistance (Figure S1) (20).

Due to the big variety of flow volume patterns after CEA, there is no agreement on a threshold that should entail intraoperative revision. Most importantly, flow measurements are not suitable to detect residual plaques or non-occluding thrombi.

\section{Angioscopy}

With angioscopy, completion control is performed immediately prior to completion of the reconstruction and therefore before blood flow is restored.

After all vessels are back vented and flushed with heparinized saline solution, a hysteroscope $(21,22)$ or choledochoscope (23) is inserted and the lumen of the endarterectomized artery is inspected. Naylor et al. proclaimed that intima flaps exceeding $3 \mathrm{~mm}$ in length should be corrected and all residual thrombus to be aspirated $(21,22)$.

The fact that angioscopy is performed before restoration of the blood flow holds advantages and disadvantages compared to measures performed thereafter. The major strength of the technique is that residual thrombi persisting after irrigation can be prevented from embolizing into the brain (Figure S2).

A drawback of the technique is that intima flaps that appear to lie flat against the vessel wall might lift up as soon as blood flow is restored. This applies equally to residual intimal structures, which can be filiform or reticular and therefore invisible as long as no blood is running. Therefore, it is advisable to perform angioscopy while irrigating the vessel with saline in order to simulate blood flow.

\section{Miscellaneous ICS techniques applied in CEA}

Singular reports exist on alternative techniques to control the morphologic appropriateness after CEA.

Karnik et al. reported on a small series of seven patients in whom intravascular ultrasound (IVUS) was used after CEA to control the surgical result (24). Right after the arteriotomy was performed, a guidewire was placed into the distal ICA. Endarterectomy and patch angioplasty were performed with the wire in place. After CEA was completed, the probing catheter was advanced over the guidewire up to the base of the skull. The lumen and vessel wall were examined while the catheter was retracted (24). In all except one patient, the endarterectomy site including the distal transition zone could be assessed sufficiently. No major 
defect was detected and thus no surgical correction was necessary. According to the authors, potential disadvantages of the system are the thickness of the ultrasound catheter, the capability to provide slice views only, and highintensity echoes if the probe is not positioned centrally (24). Furthermore, with the guidewire placed in an antegrade direction, it is not possible to assess the proximal end of the endarterectomy site and the proximal clamping site.

Lee et al. published their results of intraoperative indocyanine green (ICG) angiography in 6 patients. After CEA was completed, an ICG dye solution was injected intravenously and the internal surface of the artery was assessed using a microscope with an infrared filter (25). In one patient, fluttering atheroma was revealed by ICG angiography and prompted surgical correction (25). A potential advantage of this technique might be that the whole carotid bifurcation can be assessed at once. However, dissemination of this technique is likely to be limited by the availability of a microscope within the operating theatre.

\section{Methods}

\section{Search strategy}

This systematic review was conducted according to the main principles of the current PRISMA statement. Figure 3 illustrates the flow diagram of the applied search strategy.

In February 2020, the PubMed databank [medical subject headings (MESH), title, and abstract] was searched using the following search terms with Boolean operators (OR, AND): ("CEA" OR "carotid endarterectomy") AND ("intraoperative completion control" OR "doppler" OR "flowmetry" OR "angiography" OR "arteriography" OR "ultrasound" OR "IDUS" OR "angioscopy"). The reference lists of selected studies and reviews were manually searched for additional relevant articles. The search was limited to studies published in English language between 1980 and February 2020, retrieved on February 23, 2020. Abstracts of the retrieved records were screened for eligibility by the first author (CK). Subsequently, the identified full text articles were assessed with respect to inclusion and exclusion criteria. All studies providing information on either of the four ICSs (i.e., angiography, IDUS, flowmetry, angioscopy) were included in the qualitative synthesis (Table S1). The quantitative analysis considered only those studies that reported results separately for one of the four ICSs (Table 1).

\section{Inclusion criteria}

Articles were included if they contained detailed information on perioperative patient outcomes (i.e., perioperative rates of stroke, death, stroke or death). They were also included if they reported on the intraoperative revision rates associated with one specific mode of ICS.

\section{Exclusion criteria}

Studies were excluded, if they were performed before the year 1980, published not in English language, or those not performed on humans.

Furthermore, studies were excluded from the quantitative analysis, if the included patients underwent CEA with more than one mode of ICS, because the results could not be attributed to one specific ICS technique.

Studies were also excluded from the quantitative analysis, if they did not report specifically on the results of one ICS, but summarized different modes or combinations of ICSs in their analyses.

\section{Statistical analyses}

Absolute numbers of perioperative stroke, death, stroke or death, or the intraoperative revision rate for either of the ICSs (i.e., angiography, IDUS, flowmetry, angioscopy) were extracted independently from the included articles. Overall rates of stroke, death, stroke or death, and intraoperative revision were calculated including those studies providing the respective data. Because of a limited number of eligible studies (particularly for angioscopy and for assessing differences in surgical revision rates), both pooled analysis and meta-analysis were performed. A pooled analysis was performed comparing outcomes after CEA with angiography, IDUS, flowmetry, and angioscopy, with those after CEA without any ICS, by calculation of risk ratios (RR), 95\% confidence intervals (CI), and $\mathrm{P}$ values.

Meta-analyses were performed according to the MantelHaenszel method (56,57). Owing to the small number of included studies, the low event rates, and the relatively low heterogeneity of studies, fixed-effects analyses were performed, as recommended in the Cochrane Handbook for Systematic Reviews of Interventions (58). To quantify heterogeneity of studies, the $\mathrm{I}^{2}$ value was calculated (59). $\mathrm{I}^{2}$ values of $\leq 50 \%, 50-75 \%$, and $>75 \%$ were considered indicative of low, moderate, and severe heterogeneity. A P value $<0.05$ was considered to be statistically significant. 


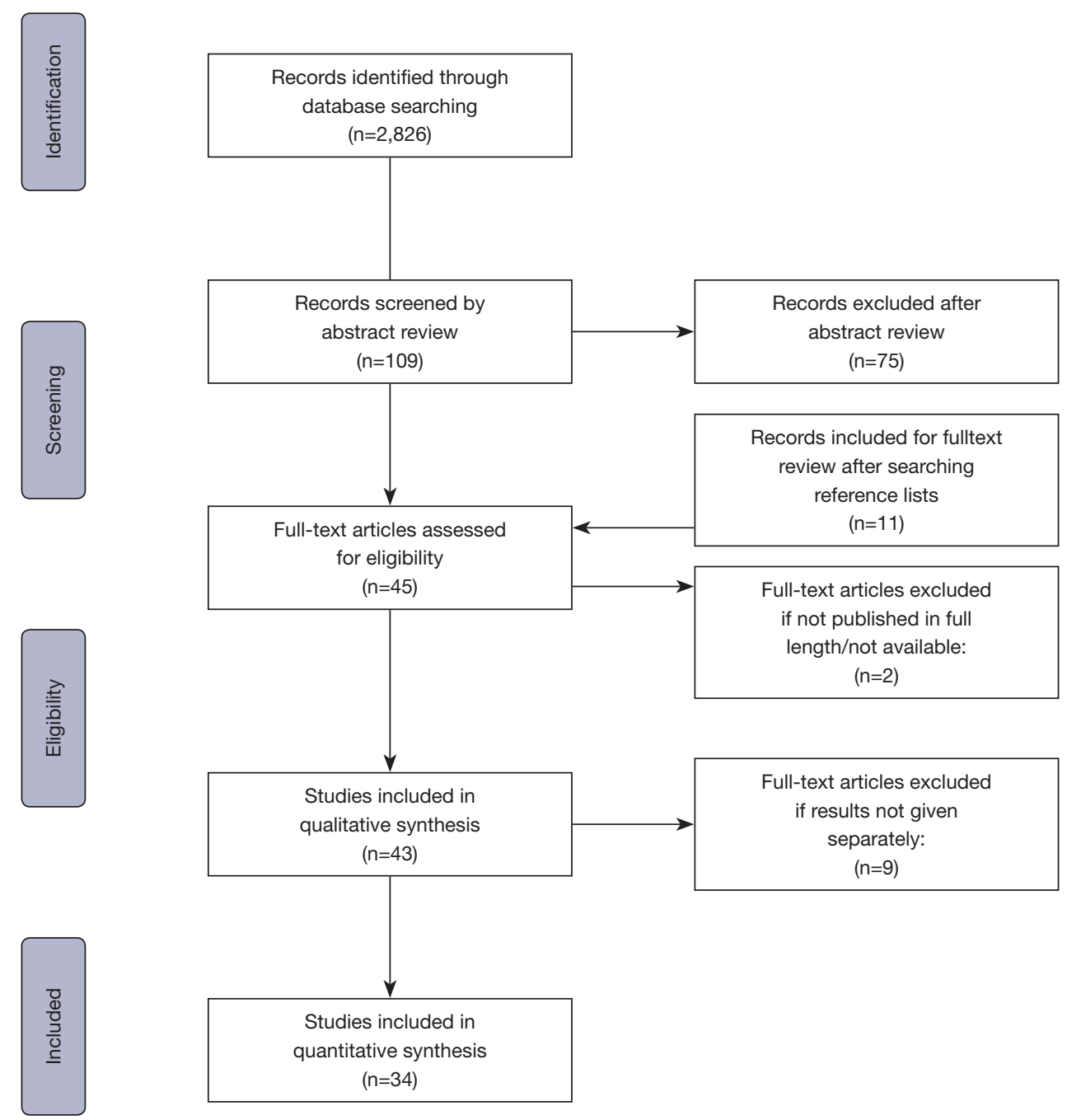

Figure 3 PRISMA 2009 flow diagram summarizing the search strategy. Search terms CEA, carotid endarterectomy, intraoperative completion control, doppler, flowmetry, angiography, arteriography, ultrasound, IDUS, and angioscopy were used to search PubMed databank between 1980 and February 2020. CEA, carotid endarterectomy; IDUS, intraoperative duplex ultrasound.

Statistical analyses were performed in $\mathrm{R}$ version 3.6.2 using the meta package (60).

\section{Results}

Initially, the PubMed database search identified 2,826 articles (Figure 3). After screening of article titles, abstracts, and reference lists, and exclusion of articles with no fulltext available, 43 articles were considered eligible for the qualitative synthesis of this review (Table S1). Exclusion of studies not reporting on results for either ICS technique separately, left 34 articles for the quantitative analysis (Table 1).
Despite a huge number of retrospective studies or prospective non-controlled case series, a confirmatory trial to assess a potential benefit of one or another means of ICS is lacking.

\section{Angiography}

Twelve articles, published between 1986 and 2019, and containing information on angiography as ICS in CEA were identified (Table 1). The median number of included patients was 232 (range, 74-48,592). A single center setting applied to the majority of studies $(\mathrm{n}=9)$, while two analyses were conducted on basis of registry data, and one article 
Table 1 Clinical outcomes after CEA using different intraoperative completion studies (quantitative synthesis)



Table 1 (continued) 
Table 1 (continued)

\begin{tabular}{|c|c|c|c|c|c|c|}
\hline Studies & $\begin{array}{c}\text { Publication } \\
\text { year }\end{array}$ & $\mathrm{N}$ & $\begin{array}{l}\text { Stroke, } \\
\text { n/N (\%) }\end{array}$ & $\begin{array}{l}\text { Death, } \\
\text { n/N (\%) }\end{array}$ & $\begin{array}{c}\text { Stroke/death, } \\
n / N(\%)\end{array}$ & $\begin{array}{c}\text { Revision, } \\
\text { n/N (\%) }\end{array}$ \\
\hline Rockman et al. (33) ${ }^{\dagger}$ & 2007 & 585 & $21 / 585(3.6)$ & - & $25 / 585(4.3)$ & - \\
\hline Yuan et al. (53) & 2014 & 285 & 3/285 (1.1) & - & - & $11 / 285$ (3.9) \\
\hline Knappich et al. $(11)^{\dagger}$ & 2017 & 15,980 & - & - & $273 / 15,980(1.7)$ & - \\
\hline \multicolumn{7}{|l|}{ Flowmetry } \\
\hline Rockman et al. (33) ${ }^{\dagger}$ & 2007 & 2,331 & $84 / 2,331(3.6)$ & - & $100 / 2,331(4.3)$ & - \\
\hline Knappich et al. (11) ${ }^{\dagger}$ & 2017 & 14,481 & - & - & $262 / 14,481(1.8)$ & - \\
\hline Zannetti et al. (30) & 1999 & 299 & $2 / 299(0.7)$ & - & - & $16 / 299(5.4)$ \\
\hline Lennard et al. (55) & 1999 & 252 & 4/252 (1.6) & $3 / 252(1.2)$ & $7 / 252(2.8)$ & $12 / 252(4.8)$ \\
\hline Osman et al. (23) & 2001 & 110 & $0 / 110(0)$ & $0 / 110(0)$ & $0 / 110(0)$ & $10 / 110(9.1)$ \\
\hline Sharpe et al. (21) & 2012 & 1,600 & $28 / 1,600(1.7)$ & $11 / 1,600(0.7)$ & $33 / 1,600(2.1)$ & $135 / 1,600(8.4)$ \\
\hline Total & & 2,291 & $34 / 2,261(1.5)$ & 14/1,962 (0.7) & 40/1,962 (2.0) & $182 / 2,291(7.9)$ \\
\hline
\end{tabular}

${ }^{\dagger}$, studies comparing CEA with respective ICS to CEA without any ICS, and therefore included in meta-analyses. $\mathrm{N}$ indicates number of patients involved; $n$, number of patients with feature; $n / N(\%)$, percentage of patients with information on respective outcome available; IDUS, intraoperative duplex ultrasound; ICS, intraoperative completion study.

reported on a multicenter analysis. Half of the studies $(\mathrm{n}=5)$ had a prospective study design, but there was no RCT.

In total, the identified articles reported on 53,218 patients undergoing CEA with angiography as ICS. The mean rates of perioperative stroke, death, and stroke or death were $1.5 \%, 0.4 \%$, and $1.7 \%$. An intraoperative surgical revision and correction of defects was performed in $6.1 \%$.

Only three studies compared outcomes after CEA with angiography directly to those without any ICS $(26,31,35)$. In a historic study published in 1986, Courbier et al. compared their results of CEA with intraoperative angiography to those without completion control (26). Angiography was used in the last 100 patients, whereas prior to that no angiography was used in 206 consecutive patients. The authors found that intraoperative angiography reduced the perioperative mortality from $2.9 \%$ to $1 \%$, the permanent stroke rate from $1.9 \%$ to $1 \%$, and the temporary stroke rate from $6.3 \%$ to $1 \%$ (26).

More recent trials were not able to obtain results of comparable distinctiveness. A prospective study including 914 CEAs and published in 2006 aimed to investigate the difference in outcomes after routine and selective use of angiographic completion control (32). No significant difference was found with respect to the stroke rate and the rate of stroke or death within 30 days from surgery. The authors concluded that routine completion angiography during CEA is not mandatory (32).

A recently published secondary data analysis of the German statutory quality assurance database demonstrated for the first time that the utilization of intraoperative angiography or duplex ultrasound was associated with lower rates of in-hospital stroke or death under real world conditions in Germany. Besides that, significant associations with lower risks of any stroke, death, and major stroke or death, each until hospital discharge were shown. Despite the limitations of a retrospective investigation, with 142,074 patients included, the analysis to date represents the largest series on this topic (11). 
Common limitations applying to most studies addressing the impact of angiography on the clinical outcome after CEA are small patient numbers and often a retrospective study design. A confirmatory RCT is missing.

\section{IDUS}

The aforementioned limitations equally apply to studies on the effect of IDUS on the perioperative event rates after CEA.

A total of 23 studies, published between 1988 and 2017, were identified. All except two studies $(n=21)$ were single center studies and the median patient number was 106 $[35-15,980]$. Seven studies were conducted in a prospective fashion, but no RCT was among those.

The included studies covered a total of 20,030 patients who underwent CEA with IDUS. The mean rates of perioperative stroke, death, and stroke or death were $1.8 \%$, $0.9 \%$, and $1.9 \%$. An intraoperative surgical revision was documented in $5.9 \%$.

Rockman et al. performed a retrospective study of 9,278 CEAs included in the New York Carotid Artery Surgery (NYCAS) study (33). Some form of ICS was performed in 3,318 cases with doppler flowmetry being used in 2,331 cases. IDUS was used in 585 cases and angiography was applied in 178 procedures. None of the techniques showed a significant association with the perioperative stroke rate (33).

Lingenfelter et al. performed a prospective study on 53 patients to assess differences in sensitivities and specificities of angiography, IDUS, and doppler flowmetry. IDUS was found to possess the highest sensitivity and specificity (100\% each), followed by angiography (66\% and $95.7 \%)$ and doppler flowmetry (16\% and 97.8\%) (61).

Despite IDUS presumably being the completion study technique with the highest sensitivity to detect minor defects, it is still unclear if correction of those can reduce the perioperative stroke rate. In fact it has been shown that there is no statistically significant relationship between the presence of minor residual defects in IDUS and restenosis or occlusion of the arteries assessed (38).

The only study demonstrating a significant association of IDUS with a beneficial patient outcome was the abovementioned secondary data analysis of the German statutory quality assurance database, including 142,074 patients. Application of IDUS was independently associated with lower rates of stroke or death, any stroke, death, and major stroke or death, each until hospital discharge (11). Although adjusted for possible confounders, the limitations of a retrospective study equally apply to this as to most other investigations on this topic.

\section{Flowmetry}

Articles reporting on patients who underwent CEA with flowmetry as ICS were restricted to a number of two. Those were published in 2007 and 2017 and contained 2,331 and 14,481 patients, summing up to a total of 16,812 patients. Both studies were retrospective analyses of registry data. The mean rate of perioperative stroke was $3.6 \%$, while perioperative stroke or death occurred in $2.2 \%$.

A study involving 116 CEAs between the years 2000 and 2003 aimed to compare flowmetry to IDUS and angiography. No correlation between flowmetric results and IDUS or angiography, respectively was found. The mean flow volume measured in the ICA was $249 \mathrm{~mL} / \mathrm{min}$ with a wide variation of values $(60-750 \mathrm{~mL} / \mathrm{min})$. A low flow $(<100 \mathrm{~mL} / \mathrm{min})$ was measured in five patients, however IDUS and angiography showed normal results (62).

A retrospective study performed by Wallaert et al. on 6,115 CEAs aimed to assess the effect of different surgeons' practice patterns in the use of completion studies on the perioperative stroke or death rate (63). In 5,554 CEAs, some form of completion study was applied with doppler flowmetry being used in most of them $(n=3,520)$. The 30 -day stroke or death rates were significantly lower for surgeons who performed ICSs selectively (1.2\%) and higher in those who applied them routinely (2.4\%). After risk adjustment, the difference did not maintain statistical significance, however trends were similar. With respect to restenosis, the Kaplan-Meier survival curve demonstrated a trend toward lower rates for surgeons who used ICSs selectively or routinely compared to rare use (63).

In the aforementioned retrospective study of patients included in the NYCAS study, doppler flowmetry was used in 2,331 of 9,278 cases. Intraoperative application of doppler flowmetry alike the other techniques did not show a significant association with the perioperative stroke rate (33).

\section{Angioscopy}

Our literature research identified 5 studies reporting on angioscopy as ICS in CEA. Those were published between 1994 and 2012 and included a median of 252 [30$1,600]$ patients. Most of them $(n=4)$ had a single center setting, while only two studies had a prospective study design. Four of the studies purely described results after 
CEA with angioscopy as ICS, whereas Zannetti et al. (30) aimed at comparing angioscopy to IDUS and angiography as ICSs.

The cumulative patient number was 2,291. Mean rates of perioperative stroke, death, and stroke or death were $1.5 \%$, $0.7 \%$, and $2.0 \%$. An intraoperative surgical correction of defects was performed in $7.9 \%$.

With 1,600 CEAs included over a 15-year period, Sharpe et al. reported on the largest cohort of patients undergoing CEA with intraoperative angioscopic control. A remarkably low 30-day stroke or death rate of $2.1 \%$ was achieved (21).

An analysis of 1,305 prospectively included patients in the EVEREST trial aimed to assess the impact of technical errors on ipsilateral carotid occlusion, ipsilateral stroke, and early restenosis rate (30). Angiography was used in 1,004 and angioscopy in 299 patients. Usage of angioscopy and angiography did not show a difference with respect to the occurrence of ipsilateral carotid occlusion (OR 1.7, 95\% CI, 0.2-11.8), ipsilateral stroke (OR 0.3, 95\% CI, 0.03-1.2), and early restenosis (OR 0.4, 95\% CI, 0.04-1.5) (30).

\section{Comparison of outcomes with different ICS techniques to nonapplication of any ICS in CEA}

Table 2 summarizes the results of the pooled analyses comparing outcomes of patients who underwent CEA with angiography, IDUS, flowmetry, or angioscopy as ICSs to those who were operated upon without any ICS.

Angiography was found to be associated with lower rates of stroke (RR 0.47; 95\% CI, 0.36-0.62; $\mathrm{P}<0.0001)$ and stroke or death (RR 0.76; 95\% CI, 0.70-0.83; $\mathrm{P}<0.0001$ ) when compared to nonapplication of any ICS. Perioperative mortalities did not differ significantly (RR 0.44; $95 \%$ CI, $0.18-1.08 ; \mathrm{P}=0.07)$.

Similarly, IDUS was associated with lower rates of stroke (RR 0.56; 95\% CI, 0.43-0.73; $\mathrm{P}<0.0001$ ) and stroke or death (RR 0.83; 95\% CI, 0.74-0.93; P=0.0018), whereas mortality did not differ significantly (RR $0.84 ; 95 \%$ CI, $0.37-1.93 ; \mathrm{P}=0.69)$.

Regarding angioscopy, the pooled analysis revealed an association with a lower perioperative stroke rate (RR 0.48; 95\% CI, 0.033-0.68; $\mathrm{P}=0.0001$ ), while the rates of death (RR $0.72 ; 95 \% \mathrm{CI}, 0.29-1.77 ; \mathrm{P}=0.47$ ), and stroke or death (RR $0.90 ; 95 \% \mathrm{CI}, 0.66-1.23 ; \mathrm{P}=0.52$ ) were not different from nonapplication of ICSs.

With respect to surgical revision and correction of defects compared to angiography, angioscopy was associated with a higher rate (RR 1.29; 95\% CI, 1.07-1.54; $\mathrm{P}=0.006$ ), while no significant difference was demonstrated for IDUS (RR 0.95; 95\% CI, 0.80-1.14; $\mathrm{P}=0.59$ ).

In addition, we performed meta-analyses of all studies comparing patients undergoing CEA with one specific ICS technique to those operated upon without any ICS. A total of five studies were found comparing outcomes after CEA with angiography compared to no ICS use $(11,26,31,33,35)$. With respect to IDUS and flowmetry, only three $(11,33,43)$ and one (11) studies, stating outcomes after CEA with and without ICS, were detected. No article was identified, reporting on a comparison of angioscopy and nonapplication of ICS.

Figure 4 shows the results of our meta-analyses with the outcome defined as perioperative stroke or death.

When compared to CEA without use of any ICS, CEA with angiography (RR 0.83; 95\% CI, 0.76-0.91) and CEA with IDUS (RR 0.86; 95\% CI, 0.76-0.98) were significantly associated with lower stroke or death rates. Application of flowmetry (RR 0.90; 95\% CI, 0.80-1.02) was not associated with lower perioperative stroke or death rates. The $\mathrm{I}^{2}$ values for included studies of all meta-analyses were considered indicative of low heterogeneity.

With stroke defined as outcome event (Figure S3), only four $(26,31,33,35)$, two $(33,43)$, and one (33) studies were eligible to be included in the meta-analyses. No significant differences were revealed for angiography (RR 0.54; 95\% CI, 0.28-1.06), IDUS (RR 1.13; 95\% CI, 0.73-1.74), and flowmetry (RR 1.16; 95\% CI, 0.9-1.49) as ICSs when compared to CEA without ICS. Heterogeneity of studies was considered low.

\section{Discussion}

The present study represents the first systematic literature review and meta-analysis on ICS usage in CEA. Despite a decent number of retrospective studies and prospective case series, a lack of confirmative studies (i.e., RCTs comparing patients undergoing CEA with one specific ICS technique to CEA with another ICS technique or no ICS, respectively) has prevented carotid guidelines to mention on ICSs until recently (7-9). According to the most recently published carotid guidelines of the ESVS, evidence suggests that a selective use of quality control strategies may reduce perioperative stroke and death rates. However, due to a lack of confirmatory studies, the ESVS only gave a weak recommendation (class of recommendation IIb) to consider any kind of targeted quality control strategy (1). A stronger recommendation was published by the just 
Table 2 Clinical outcomes of CEA using different intraoperative completion studies compared to CEA without any intraoperative completion study (pooled analysis)

\begin{tabular}{|c|c|c|c|c|c|c|}
\hline Variables & $\mathrm{N}$ & $\mathrm{n}$ & $\mathrm{n} / \mathrm{N}(\%)$ & $\mathrm{RR}$ & $95 \% \mathrm{Cl}$ & $\mathrm{P}$ \\
\hline w/o & 6,737 & 212 & 3.2 & Ref. & Ref. & Ref. \\
\hline Angiography & 4,626 & 69 & 1.5 & 0.47 & $0.36-0.62$ & $<0.0001^{*}$ \\
\hline IDUS & 4,050 & 71 & 1.8 & 0.56 & $0.43-0.73$ & $<0.0001^{*}$ \\
\hline Angioscopy & 2,261 & 34 & 1.5 & 0.48 & $0.033-0.68$ & $0.0001^{*}$ \\
\hline \multicolumn{7}{|c|}{ Perioperative death } \\
\hline w/o & 702 & 7 & 1.0 & Ref. & Ref. & Ref. \\
\hline Angiography & 3,444 & 15 & 0.4 & 0.44 & $0.18-1.08$ & 0.07 \\
\hline Angioscopy & 1,962 & 14 & 0.7 & 0.72 & $0.29-1.77$ & 0.47 \\
\hline \multicolumn{7}{|c|}{ Perioperative stroke/death } \\
\hline w/o & 53,767 & 1,214 & 2.3 & Ref. & Ref. & Ref. \\
\hline Angiography & 51,272 & 879 & 1.7 & 0.76 & $0.70-0.83$ & $<0.0001^{*}$ \\
\hline IDUS & 19,344 & 363 & 1.9 & 0.83 & $0.74-0.93$ & $0.0018^{\star}$ \\
\hline Flowmetry & 16,812 & 362 & 2.1 & 0.95 & $0.85-1.07$ & 0.42 \\
\hline Angioscopy & 1,962 & 40 & 2.0 & 0.90 & $0.66-1.23$ & 0.52 \\
\hline \multicolumn{7}{|l|}{ Surgical revision } \\
\hline
\end{tabular}

Associations between different modes of intraoperative completion studies and the perioperative risks of stroke, death, stroke or death, and the intraoperative revision rate. ${ }^{*}$ indicates statistical significance. $\mathrm{N}$ indicates number of patients involved; $\mathrm{n}$, number of patients with feature; $\mathrm{n} / \mathrm{N}$ (\%), percentage of patients with information on respective outcome available; RR, risk ratio; $\mathrm{Cl}$, confidence interval; w/o, nonapplication of any intraoperative completion study; IDUS, intraoperative duplex ultrasound.

released German-Austrian carotid guidelines, stating that angiography or IDUS should be performed as ICS in CEA (10).

This recommendation is reinforced by the present study. Both, pooled and the meta-analyses showed that angiography and IDUS as ICSs are associated with significantly lower perioperative stroke or death rates after CEA. Furthermore, the pooled analyses (despite inherent limitations mentioned below) demonstrated associations with lower stroke rates for angiography, IDUS, and angioscopy as ICSs in CEA.

Notably, patients' stroke and stroke or death rates did not differ significantly, if undergoing CEA with flowmetry or without any ICS.

All these observations strongly suggest, that actual morphologic assessment of the reconstruction site is an important feature for an ICS to reduce the perioperative stroke risk. An exclusive assessment of hemodynamic parameters is prone to miss any defect not altering the blood flow. Due to the inter-individual variety of flow 
A

\section{Angiography}

\begin{tabular}{|c|c|c|c|c|c|c|c|c|c|}
\hline \multirow[b]{2}{*}{ Study } & \multicolumn{2}{|c|}{ Intervention } & \multicolumn{2}{|c|}{ Control } & & & \multirow[b]{2}{*}{$\mathbf{R R}$} & \multirow[b]{2}{*}{$95 \% \mathrm{Cl}$} & \multirow[b]{2}{*}{ weight } \\
\hline & Events & Total & Events & Total & & & & & \\
\hline Courbier et al & 3 & 100 & 20 & 206 & 1 & & 0.31 & {$[0.09 ; 1.02]$} & $1.3 \%$ \\
\hline Woelfe et al & 3 & 115 & 3 & 116 & $\frac{1}{1}$ & & 1.01 & {$[0.21 ; 4.89]$} & $0.3 \%$ \\
\hline Rockman et al & 9 & 178 & 228 & 5988 & +1 & & 1.33 & {$[0.69 ; 2.54]$} & $1.3 \%$ \\
\hline Lancelevee et al & 2 & 179 & 4 & 380 & 1 & & 1.06 & {$[0.20 ; 5.74]$} & $0.3 \%$ \\
\hline Knappich et al & 838 & 48592 & 975 & 47030 & + & & 0.83 & {$[0.76 ; 0.91]$} & $96.9 \%$ \\
\hline \multirow{3}{*}{$\begin{array}{l}\text { Fixed effect model } \\
\text { Prediction interval } \\
\text { Heterogeneity: } l^{2}=16 \%\end{array}$} & & . & & - & $\dot{\theta}$ & & 0.83 & $\begin{array}{l}{[0.76 ; 0.91]} \\
{[0.21 ; 3.47]}\end{array}$ & $100.0 \%$ \\
\hline & $\%[0 \% ; 83$ & $3 \%], p=$ & $=0.31$ & $\Gamma$ & $T$ & $T$ & & & \\
\hline & & & & 0.1 & 0.5 & 2 & 0 & & \\
\hline
\end{tabular}

B

\section{IDUS}

$\begin{array}{llr}\text { Intervention } & \text { Control } \\ \text { Events Total Events Total }\end{array}$

Lipski et al

Rockman et al

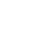

Knappich et al

$\begin{array}{rrrr}1 & 39 & 2 & 47 \\ 25 & 585 & 228 & 5988 \\ 273 & 15980 & 957 & 4703\end{array}$

Fixed effect model

Prediction interval

Heterogeneity: $I^{2}=0 \%[0 \% ; 89 \%], p=0.39$
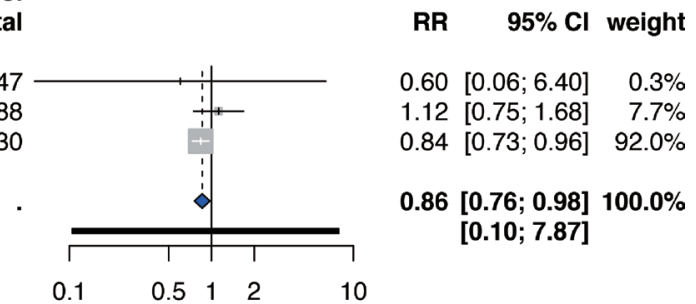

C

Flowmetry

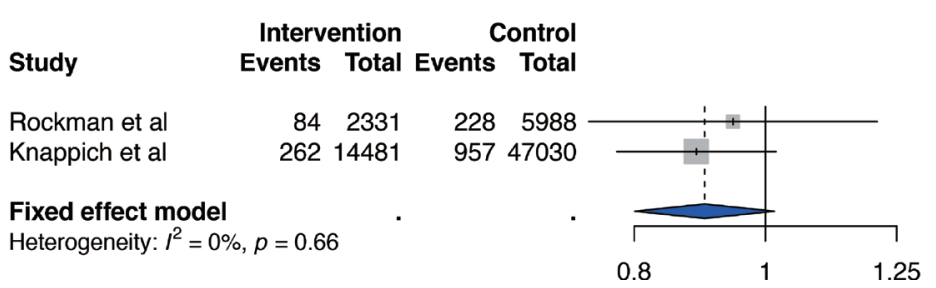

$\begin{array}{rrr}\text { RR } & 95 \% \text { Cl } & \text { weight } \\ 0.95[0.74 ; 1.21] & 22.1 \% \\ 0.89[0.78 ; 1.02] & 77.9 \% \\ 0.90[0.80 ; 1.02] & 100.0 \%\end{array}$

Figure 4 Meta-analysis of all publications comparing perioperative stroke or death rates in patients undergoing CEA with different ICSs to those treated with CEA without any ICS. Forest plots illustrating results of meta-analyses including all studies to compare CEA with angiography (A), IDUS (B), and flowmetry (C) to CEA without use of any ICS. ICS, intraoperative completion study; CEA, carotid endarterectomy; IDUS, intraoperative duplex ultrasound; RR, risk ratio; CI, confidence interval.

patterns and flow volumes after CEA, widely accepted threshold values to perform surgical revision do not exist. Flowmetry seems to contain the lowest sensitivity (16\%) to detect defects after CEA (61). The numerically largest included study, which was a secondary data analysis of the German statutory quality assurance database, equally showed flowmetry (as opposed to angiography and IDUS) not to be associated with a lower perioperative stroke rate (11). In summary, based on the currently available evidence, one cannot recommend to purely rely on flowmetry as ICS in CEA.

Although this review cannot prove causality, the reduction of perioperative strokes associated with angiography, IDUS, and angioscopy might be attributed to correction of unpleasant findings after CEA. The intraoperative revision rates did not differ significantly 
for angiography and IDUS, however were significantly elevated for angioscopy. None of the identified articles stated surgical revision rates for patients undergoing CEA exclusively with flowmetry as ICS.

Considering the intraoperative revision rate being a measure of the sensitivity to detect defects, angioscopy might have the highest sensitivity of all ICS techniques. Lingenfelter et al. tried to assess sensitivities and specificities of different ICS techniques. IDUS was found to possess higher sensitivities and specificities than angiography, followed by doppler flowmetry (61). A major limitation of the study was an erroneous calculation of sensitivities, as the possibility of false negative findings was disregarded (incorporation bias). The unknown amount of false negative findings prohibits an accurate calculation of sensitivities for all ICS techniques applied. Nevertheless, and likewise supportive of the high sensitivity of IDUS, a very recent prospective study on 150 patients undergoing CEA with both angiography and IDUS, found that IDUS detected significantly more defects requiring surgical correction, when compared to angiography (64).

Conspicuously, with respect to perioperative stroke (alone), the significant results from our pooled analysis were not replicated by the meta-analyses. This observation presumably is due to the relatively small number of included studies and the small patient numbers of most included studies in the meta-analyses, and the associated wide CIs.

This finding underlines the need for further large-scale studies to assess the effect of ICSs in CEA. Although an RCT to compare usage of different ICSs to nonapplication will hardly be feasible, a multicenter prospective registry, offering the opportunity for risk adjusted analyses would be desirable.

Looking at sample sizes of included studies, one study is standing out and relevantly affects the results for angiography, IDUS, and flowmetry (11). The secondary data analysis of the German statutory quality assurance database contributed $91.4 \%, 81.5 \%$, and $86.1 \%$ of total patients included in studies on angiography, IDUS, and flowmetry. Therefore, this study's characteristics (drawbacks as well as strengths) exceptionally apply to the present systematic review and analyses. Major limitations of the mentioned study were an observational study design, follow-up restricted to the in-hospital period, and potential underreporting. Nevertheless, data collection was prospective, nationwide, and unselected, which due to the high proportion of included patients, favorably affects the quality of present investigation (11).

\section{Limitations and strengths}

This systematic review is subject to the following limitations. Considering only articles registered in PubMed and published in English language might have implemented some availability and language bias.

Furthermore, in concordance with other reviews, the totality of evidence might underly both publication and reporting bias.

Due to the shortage of evidence, all eligible articles were included if published after the year 1980. This resulted in a relevant proportion of studies performed in the 1980s and 1990s and therefore possibly being outdated.

Additionally, as individual patient data were not available, adjustment for various perioperative variables was not feasible in the conducted analyses.

As none of the included studies was an RCT, the collectivity might underly some selection bias. On the one side, it seems possible that ICSs tend to be more frequently applied by surgeons who are specialized in vascular surgery or even in carotid surgery, potentially favoring patient outcomes. On the other side, there might exist surgeons, using ICSs selectively in challenging cases if they suspect a technical problem. This again might have introduced confounding by indication and disfavor ICS outcomes.

Furthermore, because no weighting of included studies is applied, pooled analyses do not distinguish among individual studies or subgroups, and are particularly prone to selection bias. Nevertheless, owing to the limited number of eligible studies (especially for angioscopy and for assessing differences in surgical revision rates), pooled analyses as well as meta-analyses were performed.

With respect to perioperative outcomes, the perioperative period was not defined homogenously across the included studies.

As the meta-analyses only included patients who underwent CEA with one single ICS technique, and excluded patients who were operated upon using different combinations of ICS techniques, a comparison of different combinations of ICS techniques was not possible.

Lastly, this study did not distinguish between different flowmetry techniques (i.e., doppler flowmetry, TTFM).

Despite the listed drawbacks, this systematic review represents a comprehensive overview of the available evidence on ICSs in CEA. It contains the first meta-analysis 
to demonstrate a beneficial association between the use of angiography and IDUS, and lower perioperative stroke or death rates.

\section{Conclusions}

This study represents the first systematic literature review and meta-analysis on the usage of ICSs in CEA. Our data strongly indicate angiography, IDUS, and probably angioscopy to be associated with a lower perioperative stroke risk after CEA, when compared to CEA without any ICS. Notably, the application of flowmetry was not associated with a lower perioperative stroke or death rate.

Despite the absence of a randomized controlled trial to assess the effect of ICSs on the perioperative outcome of CEA, the pursuit of perfection of any vascular surgeon should be incentive to achieve an optimal technical result for the patient. Although the majority of defects might be preempted by meticulous surgical technique, some of them (e.g., thrombus formation or plaque residuals) will not.

Today's best medical treatment might have led to a continuously decreasing carotid-related stroke risk.

Since the NNT for CEA to prevent a stroke at 5 years being as high as 6.5 in symptomatic (65) and 20 in asymptomatic patients (66), one of the highest priorities must be not to cause any harm.

Therefore, any carotid surgeon should strongly consider to implement angiography, IDUS, or probably angioscopy in his or her routine armamentarium. Flowmetry is not suitable to improve perioperative stroke rates.

\section{Acknowledgments}

We would like to thank Prof. Ross Naylor, Department of Vascular Surgery at Leicester Royal Infirmary, Leicester, United Kingdom, who kindly provided the angioscopic image depicted in supplemental Figure S2.

Funding: None.

\section{Footnote}

Provenance and Peer Review: This article was commissioned by the Guest Editor (Kosmas I. Paraskevas) for the series "Carotid Artery Stenosis and Stroke - Prevention and Treatment Part II" published in Annals of Translational Medicine. The article has undergone external peer review.

Reporting Checklist: The authors have completed the
PRISMA reporting checklist. Available at http://dx.doi. org/10.21037/atm-20-2931

Conflicts of Interest: All authors have completed the ICMJE uniform disclosure form (available at http://dx.doi. org/10.21037/atm-20-2931). The series "Carotid Artery Stenosis and Stroke - Prevention and Treatment Part II" was commissioned by the editorial office without any funding or sponsorship. CK reports personal fees from Medistim ASA Norway, outside the submitted work. HHE reports grants from Medistim Company, during the conduct of the study. The other authors have no other conflicts of interest to declare.

Ethical Statement: The authors are accountable for all aspects of the work in ensuring that questions related to the accuracy or integrity of any part of the work are appropriately investigated and resolved.

Open Access Statement: This is an Open Access article distributed in accordance with the Creative Commons Attribution-NonCommercial-NoDerivs 4.0 International License (CC BY-NC-ND 4.0), which permits the noncommercial replication and distribution of the article with the strict proviso that no changes or edits are made and the original work is properly cited (including links to both the formal publication through the relevant DOI and the license). See: https://creativecommons.org/licenses/by-nc-nd/4.0/.

\section{References}

1. Naylor AR, Ricco JB, de Borst GJ, et al. Management of Atherosclerotic Carotid and Vertebral Artery Disease: 2017 Clinical Practice Guidelines of the European Society for Vascular Surgery (ESVS). Eur J Vasc Endovasc Surg 2018;55:3-81.

2. Lokuge $\mathrm{K}$, de Waard DD, Halliday A, et al. Meta-analysis of the procedural risks of carotid endarterectomy and carotid artery stenting over time. Br J Surg 2018;105:26-36.

3. Munster AB, Franchini AJ, Qureshi MI, et al. Temporal trends in safety of carotid endarterectomy in asymptomatic patients: systematic review. Neurology 2015;85:365-72.

4. Kallmayer MA, Tsantilas P, Knappich C, et al. Trends und Ergebnisse der Karotischirurgie in Deutschland 20032013. Gefasschirurgie 2015;20:289-98.

5. Kernan WN, Ovbiagele B, Black HR, et al. Guidelines for the prevention of stroke in patients with stroke and transient ischemic attack: a guideline for healthcare 
professionals from the American Heart Association/ American Stroke Association. Stroke 2014;45:2160-236.

6. European Stroke Organisation Executive Committee, ESO Writing Committee. Guidelines for management of ischaemic stroke and transient ischaemic attack 2008. Cerebrovasc Dis 2008;25:457-507.

7. Ricotta JJ, Aburahma A, Ascher E, et al. Updated Society for Vascular Surgery guidelines for management of extracranial carotid disease: executive summary. J Vasc Surg 2011;54:832-6.

8. Tendera M, Aboyans V, Bartelink ML, et al. ESC Guidelines on the diagnosis and treatment of peripheral artery diseases: Document covering atherosclerotic disease of extracranial carotid and vertebral, mesenteric, renal, upper and lower extremity arteries: the Task Force on the Diagnosis and Treatment of Peripheral Artery Diseases of the European Society of Cardiology (ESC). Eur Heart J 2011;32:2851-906.

9. Eckstein HH, Kuhnl A, Dorfler A, et al. The diagnosis, treatment and follow-up of extracranial carotid stenosis. Dtsch Arztebl Int 2013;110:468-76.

10. Eckstein HH, Kuhnl A, Berkefeld J, et al. S3Leitlinie zur Diagnostik, Therapie und Nachsorge der extracraniellen Carotisstenose 2020. Available online: https://www.awmf.org/uploads/tx_szleitlinien/004-0281_ extracranielle-Carotisstenose-Diagnostik-TherapieNachsorge_2020-02_03.pdf

11. Knappich C, Kuehnl A, Tsantilas P, et al. Intraoperative Completion Studies, Local Anesthesia, and Antiplatelet Medication Are Associated With Lower Risk in Carotid Endarterectomy. Stroke 2017;48:955-62.

12. Subramaniam RM, Suarez-Cuervo C, Wilson RF, et al. Effectiveness of Prevention Strategies for ContrastInduced Nephropathy: A Systematic Review and Metaanalysis. Ann Intern Med 2016;164:406-16.

13. Weisbord SD, Gallagher M, Jneid H, et al. Outcomes after Angiography with Sodium Bicarbonate and Acetylcysteine. N Engl J Med 2018;378:603-14.

14. Derdeyn CP, Moran CJ, Cross DT, et al. Intraoperative digital subtraction angiography: a review of 112 consecutive examinations. Am J Neuroradiol 1995;16:307-18.

15. Ascher E, Markevich N, Kallakuri S, et al. Intraoperative carotid artery duplex scanning in a modern series of 650 consecutive primary endarterectomy procedures. J Vasc Surg 2004;39:416-20.

16. Parsa P, Hodgkiss-Harlow K, Bandyk DF. Interpretation of intraoperative arterial duplex ultrasound testing. Semin
Vasc Surg 2013;26:105-10.

17. Mays BW, Towne JB, Seabrook GR, et al. Intraoperative carotid evaluation. Arch Surg 2000;135:525-8.

18. Schanzer A, Hoel A, Owens CD, et al. Restenosis after carotid endarterectomy performed with routine intraoperative duplex ultrasonography and arterial patch closure: a contemporary series. Vasc Endovascular Surg 2007;41:200-5.

19. Mullenix PS, Tollefson DF, Olsen SB, et al. Intraoperative duplex ultrasonography as an adjunct to technical excellence in 100 consecutive carotid endarterectomies. Am J Surg 2003;185:445-9.

20. Aleksic M, Heckenkamp J, Gawenda M, et al. Pulsatility index determination by flowmeter measurement: a new indicator for vascular resistance? Eur Surg Res 2004;36:345-9.

21. Sharpe R, Sayers RD, McCarthy MJ, et al. The war against error: a 15 year experience of completion angioscopy following carotid endarterectomy. Eur J Vasc Endovasc Surg 2012;43:139-45.

22. Naylor AR, Sayers RD, McCarthy MJ, et al. Closing the loop: a 21-year audit of strategies for preventing stroke and death following carotid endarterectomy. Eur J Vasc Endovasc Surg 2013;46:161-70.

23. Osman HY, Gibbons CP. Completion angioscopy following carotid endarterectomy by the eversion technique or the standard longitudinal arteriotomy with patch closure. Ann R Coll Surg Engl 2001;83:149-53.

24. Karnik R, Ammerer HP, Winkler WB, et al. Initial experience with intravascular ultrasound imaging during carotid endarterectomy. Stroke 1994;25:35-9.

25. Lee CH, Jung YS, Yang HJ, et al. An innovative method for detecting surgical errors using indocyanine green angiography during carotid endarterectomy: a preliminary investigation. Acta Neurochir (Wien) 2012;154:67-73.

26. Courbier R, Jausseran JM, Reggi M, et al. Routine intraoperative carotid angiography: its impact on operative morbidity and carotid restenosis. J Vasc Surg 1986;3:343-50.

27. Bredenberg CE, Iannettoni $M$, Rosenbloom M, et al. Operative angiography by intraarterial digital subtraction angiography: a new technique for quality control of carotid endarterectomy. J Vasc Surg 1989;9:530-4.

28. Donaldson MC, Ivarsson BL, Mannick JA, et al. Impact of completion angiography on operative conduct and results of carotid endarterectomy. Ann Surg 1993;217:682-7.

29. Westerband A, Mills JL, Berman SS, et al. The influence of routine completion arteriography on outcome following 
carotid endarterectomy. Ann Vasc Surg 1997;11:14-9.

30. Zannetti S, Cao P, De Rango P, et al. Intraoperative assessment of technical perfection in carotid endarterectomy: a prospective analysis of 1305 completion procedures. Collaborators of the EVEREST study group. Eversion versus standard carotid endartectomy. Eur J Vasc Endovasc Surg 1999;18:52-8.

31. Woelfle KD, Bruijnen $\mathrm{H}, \mathrm{Neu} J$, et al. The role of intraoperative digital subtraction angiography for quality control of standard carotid endarterectomy using patch angioplasty. Cardiovasc Surg 2002;10:116-22.

32. Pratesi C, Dorigo W, Troisi N, et al. Routine completion angiography during carotid endarterectomy is not mandatory. Eur J Vasc Endovasc Surg 2006;32:369-73.

33. Rockman CB, Halm EA. Intraoperative imaging: does it really improve perioperative outcomes of carotid endarterectomy? Semin Vasc Surg 2007;20:236-43.

34. Ricco JB, Regnault de la Mothe G, Fujita S, et al. Impact of routine completion angiography on the results of primary carotid endarterectomy: a prospective study in a teaching hospital. Eur J Vasc Endovasc Surg 2011;41:579-88.

35. Lancelevee J, Maurel B, Gaudin M, et al. Is it mandatory to carry out completion arteriography after carotid endarterectomy with patch angioplasty? Ann Vasc Surg 2013;27:719-26.

36. Wieker CM, Harcos K, Ronellenfitsch U, et al. Impact of routine completion angiography on outcome after carotid endarterectomy. J Vasc Surg 2019;69:824-31.

37. Schwartz RA, Peterson GJ, Noland KA, et al. Intraoperative duplex scanning after carotid artery reconstruction: a valuable tool. J Vasc Surg 1988;7:620-4.

38. Sawchuk AP, Flanigan DP, Machi J, et al. The fate of unrepaired minor technical defects detected by intraoperative ultrasonography during carotid endarterectomy. J Vasc Surg 1989;9:671-5.

39. Bandyk DF, Mills JL, Gahtan V, et al. Intraoperative duplex scanning of arterial reconstructions: fate of repaired and unrepaired defects. J Vasc Surg 1994;20:426-32.

40. Baker WH, Koustas G, Burke K, et al. Intraoperative duplex scanning and late carotid artery stenosis. J Vasc Surg 1994;19:829-32.

41. Yu A, Gregory D, Morrison L, et al. The role of intraoperative duplex imaging in arterial reconstructions. Am J Surg 1996;171:500-1.

42. Papanicolaou G, Toms C, Yellin AE, et al. Relationship between intraoperative color-flow duplex findings and early restenosis after carotid endarterectomy: a preliminary report. J Vasc Surg 1996;24:588-95.

43. Lipski DA, Bergamini TM, Garrison RN, et al. Intraoperative duplex scanning reduces the incidence of residual stenosis after carotid endarterectomy. J Surg Res 1996;60:317-20.

44. Walker RA, Fox AD, Magee TR, et al. Intraoperative duplex scanning as a means of quality control during carotid endarterectomy. Eur J Vasc Endovasc Surg 1996;11:364-7.

45. Dorffner R, Metz VM, Trattnig S, et al. Intraoperative and early postoperative colour Doppler sonography after carotid artery reconstruction: follow-up of technical defects. Neuroradiology 1997;39:117-21.

46. Steinmetz OK, MacKenzie K, Nault P, et al. Intraoperative duplex scanning for carotid endarterectomy. Eur J Vasc Endovasc Surg 1998;16:153-8.

47. Padayachee TS, Brooks MD, Modaresi KB, et al. Intraoperative high resolution duplex imaging during carotid endarterectomy: which abnormalities require surgical correction? Eur J Vasc Endovasc Surg 1998;15:387-93.

48. Seelig MH, Oldenburg WA, Chowla A, et al. Use of intraoperative duplex ultrasonography and routine patch angioplasty in patients undergoing carotid endarterectomy. Mayo Clin Proc 1999;74:870-6.

49. Panneton JM, Berger MW, Lewis BD, et al. Intraoperative duplex ultrasound during carotid endarterectomy. Vasc Surg 2001;35:1-9.

50. Ascher E, Markevich N, Hingorani AP, et al. Internal carotid artery flow volume measurement and other intraoperative duplex scanning parameters as predictors of stroke after carotid endarterectomy. J Vasc Surg 2002;35:439-44.

51. Padayachee TS, Arnold JA, Thomas N, et al. Correlation of intra-operative duplex findings during carotid endarterectomy with neurological events and recurrent stenosis at one year. Eur J Vasc Endovasc Surg 2002;24:435-9.

52. Ott C, Heller G, Odermatt M, et al. Intraoperative duplex ultrasonography in carotid endarterectomy: the impact on indication for immediate revision and intermediate-term outcome. Vasa 2008;37:151-6.

53. Yuan JY, Durward QJ, Pary JK, et al. Use of intraoperative duplex ultrasonography for identification and patch repair of kinking stenosis after carotid endarterectomy: a singlesurgeon retrospective experience. World Neurosurg 2014;81:334-43.

54. Gaunt ME, Naylor AR, Ratliff DA, et al. Role of 
completion angioscopy in detecting technical error after carotid endarterectomy. Br J Surg 1994;81:42-4.

55. Lennard N, Smith JL, Gaunt ME, et al. A policy of quality control assessment helps to reduce the risk of intraoperative stroke during carotid endarterectomy. Eur J Vasc Endovasc Surg 1999;17:234-40.

56. Mantel N, Haenszel W. Statistical aspects of the analysis of data from retrospective studies of disease. J Natl Cancer Inst 1959;22:719-48.

57. Robins J, Greenland S, Breslow NE. A general estimator for the variance of the Mantel-Haenszel odds ratio. Am J Epidemiol 1986;124:719-23.

58. Higgins JPT, Thomas J, Chandler J, et al. Cochrane Handbook for Systematic Reviews of Interventions version 6.0 (updated July 2019). Available online: www.training. cochrane.org/handbook

59. Huedo-Medina TB, Sanchez-Meca J, Marin-Martinez F, et al. Assessing heterogeneity in meta-analysis: Q statistic or I2 index? Psychol Methods 2006;11:193-206.

60. Balduzzi S, Rucker G, Schwarzer G. How to perform a meta-analysis with R: a practical tutorial. Evid Based Ment Health 2019;22:153-60.

61. Lingenfelter KA, Fuller BC, Sullivan TM. Intraoperative assessment of carotid endarterectomy: a comparison of techniques. Ann Vasc Surg 1995;9:235-40.

62. Winkler GA, Calligaro KD, Kolakowski S, et al. Comparison of intraoperative completion flowmeter versus duplex ultrasonography and contrast arteriography for carotid endarterectomy. Vasc Endovascular Surg 2006;40:482-6.

63. Wallaert JB, Goodney PP, Vignati JJ, et al. Completion imaging after carotid endarterectomy in the Vascular Study Group of New England. J Vasc Surg 2011;54:37685, 85.e1-3.

64. Knappich C, Schmid S, Tsantilas P, et al. Prospective Comparison of Duplex Ultrasound and Angiography for Intra-operative Completion Studies after Carotid Endarterectomy. Eur J Vasc Endovasc Surg 2020;59:881-9.

65. Rothwell PM, Eliasziw M, Gutnikov SA, et al. Analysis of pooled data from the randomised controlled trials of endarterectomy for symptomatic carotid stenosis. Lancet 2003;361:107-16.

66. Naylor AR. Time to rethink management strategies in asymptomatic carotid artery disease. Nat Rev Cardiol 2011;9:116-24.
Cite this article as: Knappich C, Lang T, Tsantilas P, Schmid S, Kallmayer M, Haller B, Eckstein HH. Intraoperative completion studies in carotid endarterectomy: systematic review and meta-analysis of techniques and outcomes. Ann Transl Med 2021;9(14):1201. doi: 10.21037/atm-20-2931 


\section{Supplementary}

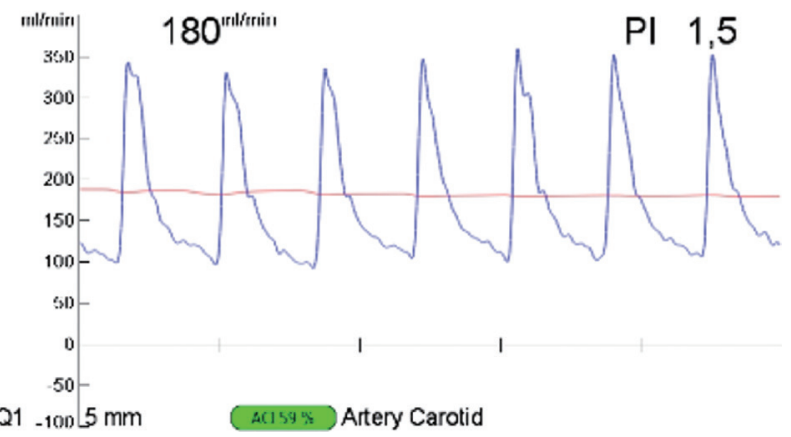

Figure S1 Flowmetry. The pulsatility index (PI) is expressed as the ratio of the flow volume amplitude and mean flow volume and serves as an estimate for the peripheral resistance.

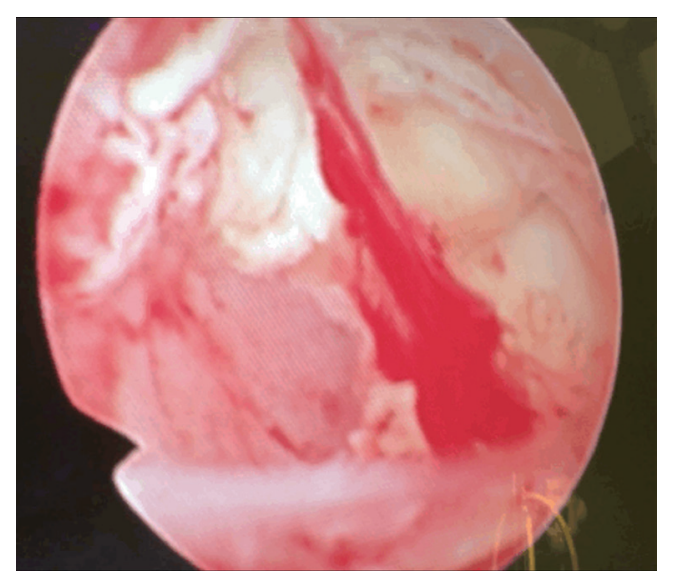

Figure S2 Angioscopy. Angioscopic image of a retained thrombus attached to the common carotid artery despite previous irrigation with heparinized saline solution. (Kindly provided by Prof. Ross Naylor, Department of Vascular Surgery at Leicester Royal Infirmary, Leicester, United Kingdom). 


\begin{tabular}{|c|c|c|c|c|c|c|c|c|c|c|c|}
\hline \multirow[b]{2}{*}{ Studies } & \multirow[b]{2}{*}{$\begin{array}{c}\text { Publication } \\
\text { year }\end{array}$} & \multirow[b]{2}{*}{$\begin{array}{l}\text { Patient } \\
\text { number }\end{array}$} & \multirow[b]{2}{*}{ Setting } & \multirow[b]{2}{*}{ Study design } & \multirow[b]{2}{*}{ Intervention } & \multicolumn{6}{|c|}{ Outcome measures assessed } \\
\hline & & & & & & Periop. stroke & Periop. death & $\begin{array}{c}\text { Periop. stroke/ } \\
\text { death }\end{array}$ & $\begin{array}{l}\text { Surgical } \\
\text { revision }\end{array}$ & $\begin{array}{c}\text { Detection of } \\
\text { defects }\end{array}$ & $\begin{array}{l}\text { Restenosis } \\
\text { during FU }\end{array}$ \\
\hline \multicolumn{12}{|l|}{ Angiography } \\
\hline Bredenberg et al. (27) & 1989 & 50 & Single center & $\mathrm{n} / \mathrm{a}$ & Angio & + & + & + & + & + & + \\
\hline Donaldson et al. (28) & 1993 & 410 & Single center & Prospective & Angio & + & + & + & + & + & + \\
\hline Lohr et al. $(67)^{\#}$ & 1995 & 145 & Single center & Retrospective & Angio vs. w/o & + & + & + & + & + & - \\
\hline Westerband et al. (29) & 1997 & 154 & Single center & Retrospective & Angio & + & + & + & + & + & + \\
\hline Zannetti et al. (30) & 1999 & 1004 & Multicenter & Prospective & Angio vs. IDUS vs. angioscopy & + & - & - & + & - & - \\
\hline Pross et al. $(69)^{\#}$ & 2001 & 380 & Single center & Retrospective & Angio vs. Angio and IDUS vs. IDUS & + & + & + & + & + & + \\
\hline Woelfle et al. (31) & 2002 & 115 & Single center & Prospective & Angio vs. w/o & + & + & - & + & + & + \\
\hline Valenti et al. $(70)^{\#}$ & 2003 & 141 & Single center & $\mathrm{n} / \mathrm{a}$ & Angio and IDUS & + & + & + & + & + & - \\
\hline Pratesi et al. (32) & 2006 & 430 & Single center & Prospective & Angio vs. selective angio & + & + & + & + & - & + \\
\hline Rockman et al. (33) & 2007 & 178 & Registry & Retrospective & Any vs. angio vs. doppler vs. IDUS vs. w/o & + & + & + & - & - & - \\
\hline Ricco et al. (34) & 2011 & 1179 & Single center & Prospective & Angio & + & + & + & + & + & + \\
\hline Lancelevee et al. (35) & 2013 & 179 & Single center & Retrospective & Angio vs. w/o & + & + & - & + & + & + \\
\hline Knappich et al. (11) & 2017 & 51,219 & Registry & Retrospective & Angio vs. IDUS vs. Flowmetry vs. w/o & - & - & + & - & - & - \\
\hline Wieker et al. (36) & 2019 & 827 & Single center & Retrospective & Angio & + & + & + & + & - & + \\
\hline \multicolumn{12}{|l|}{ IDUS } \\
\hline Schwartz et al. (37) & 1988 & 79 & Single center & Prospective & IDUS & + & + & + & + & + & - \\
\hline Sawchuk et al. (38) & 1989 & 80 & Single center & $\mathrm{n} / \mathrm{a}$ & IDUS & + & + & + & + & + & + \\
\hline Kinney et al. $(71)^{\#}$ & 1993 & 410 & Single center & Prospective & IDUS vs. IDUS and angio vs. w/o & + & + & + & + & + & + \\
\hline Hoff et al. $(72)^{\#}$ & 1994 & 44 & Single center & Prospective & IDUS vs. IDUS and angio & + & - & - & + & + & + \\
\hline Brandyk et al. (39) & 1994 & 210 & Single center & $\mathrm{n} / \mathrm{a}$ & IDUS & + & - & - & - & + & - \\
\hline Baker et al. (40) & 1994 & 316 & Single center & Retrospective & IDUS & + & + & + & + & + & + \\
\hline Lingenfelter et al. (61) & 1995 & 53 & Single center & Prospective & Angio and IDUS and flowmetry & + & + & - & + & + & + \\
\hline Yu et al. (41) & 1996 & 35 & Single center & $\mathrm{n} / \mathrm{a}$ & IDUS & + & - & - & + & + & - \\
\hline Papanicolaou et al. (42) & 1996 & 86 & Single center & Prospective & IDUS & + & - & - & + & + & + \\
\hline Dorffner (45) & 1997 & 50 & Single center & Prospective & IDUS & + & - & - & + & + & - \\
\hline Steinmetz et al. (46) & 1998 & 100 & Single center & Retrospective & IDUS & + & + & + & + & + & - \\
\hline Payadachee et al. (47) & 1998 & 106 & Single center & $\mathrm{n} / \mathrm{a}$ & IDUS & + & + & + & + & + & - \\
\hline Seelig et al. (48) & 1999 & 102 & Single center & Retrospective & IDUS & + & + & + & + & + & + \\
\hline Mays et al. (17) & 2000 & 100 & Single center & Prospective & IDUS & + & + & + & + & + & + \\
\hline Pross et al. $(69)^{\#}$ & 2001 & 380 & Single center & Retrospective & Angio vs. Angio and IDUS vs. IDUS & + & + & + & + & + & + \\
\hline Panneton et al. (49) & 2001 & 155 & Single center & Retrospective & IDUS & + & + & + & + & + & - \\
\hline Ascher et al. (50) & 2002 & 197 & Single center & Prospective & IDUS & + & + & + & + & + & - \\
\hline Mullenix et al. (19) & 2002 & 100 & Single center & Retrospective & IDUS & + & + & + & + & + & + \\
\hline Padayachee et al. (51) & 2002 & 244 & Single center & Prospective & IDUS & + & + & + & + & + & + \\
\hline Valenti et al. $(70)^{\#}$ & 2003 & 141 & Single center & Prospective & Angio and IDUS & + & + & + & + & + & - \\
\hline Ascher et al. (15) & 2004 & 650 & Single center & $\mathrm{n} / \mathrm{a}$ & IDUS & + & + & + & + & + & - \\
\hline Winkler et al. (62) & 2007 & 116 & Single center & $\mathrm{n} / \mathrm{a}$ & IDUS and flowmetry and angio & + & + & + & + & + & + \\
\hline Schanzer et al. (18) & 2007 & 407 & Single center & Retrospective & IDUS & + & + & + & + & + & + \\
\hline Rockman et al. (33) & 2007 & 585 & Registry & Retrospective & Any vs. angio vs. doppler vs. IDUS vs. w/o & + & + & + & - & - & - \\
\hline Ott et al. (52) & 2008 & 74 & Single center & Prospective & IDUS & + & + & + & + & - & - \\
\hline Yuan et al. (53) & 2014 & 285 & Single center & Retrospective & IDUS & + & + & + & + & + & + \\
\hline Knappich et al. (11) & 2017 & 18,889 & Registry & Retrospective & Angio vs. IDUS vs. flowmetry vs. w/o & - & - & + & - & - & - \\
\hline \multicolumn{12}{|l|}{ Flowmetry } \\
\hline Bandyk et al. (73) & 1988 & 235 & Single center & Prospective & Angio and flowmetry & + & + & + & + & + & + \\
\hline Rockman et al. (33) & 2007 & 2,331 & Registry & Retrospective & Any vs. angio vs. doppler vs. IDUS vs. w/o & + & + & + & - & - & - \\
\hline Knappich et al. (11) & 2017 & 18,878 & Registry & Retrospective & Angio vs. IDUS vs. flowmetry vs. w/o & - & - & + & - & - & - \\
\hline \multicolumn{12}{|l|}{ Angioscopy } \\
\hline Gaunt et al. (54) & 1994 & 30 & Single center & Retrospective & Angioscopy & + & - & - & + & - & - \\
\hline Branchereau $(68)^{\#}$ & 1995 & 103 & Single center & $\mathrm{n} / \mathrm{a}$ & Angio and angioscopy & + & + & + & + & + & - \\
\hline Zannetti et al. (30) & 1999 & 299 & Multicenter & Prospective & Angio vs. IDUS vs. angioscopy & + & - & - & + & - & + \\
\hline Lennard et al. (55) & 1999 & 252 & Single center & Prospective & Angioscopy & + & + & + & + & + & - \\
\hline Osman et al. (23) & 2001 & 110 & Single center & Retrospective & Angioscopy & + & + & + & + & + & - \\
\hline Sharpe et al. (21) & 2012 & 1,600 & Single center & Retrospective & Angioscopy & + & + & + & + & - & - \\
\hline
\end{tabular}

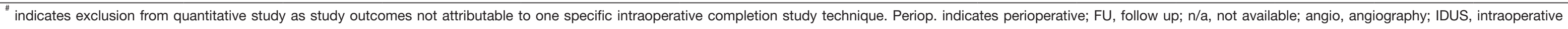
duplex ultrasound; w/o, nonapplication of any intraoperative completion study; +, outcome measure assessed for; -, outcome measure not assessed for. 


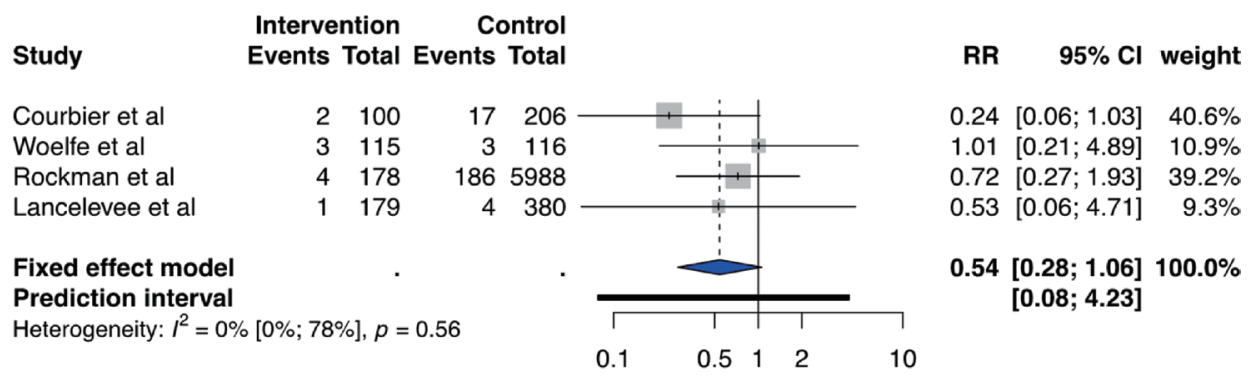

B

IDUS

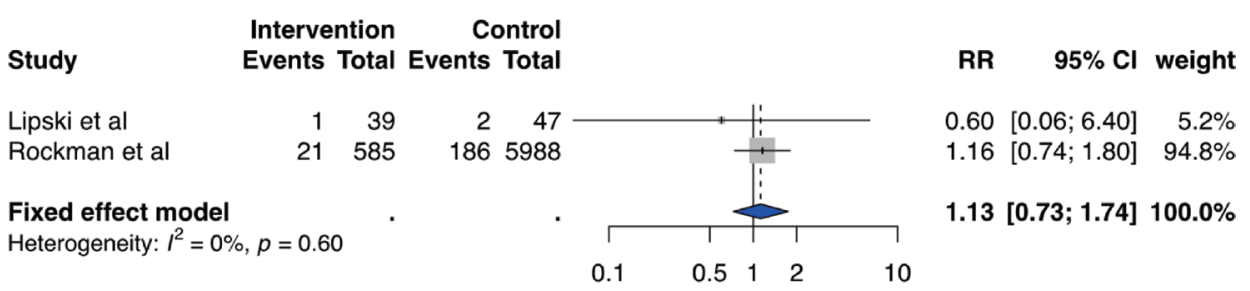

C

Flowmetry

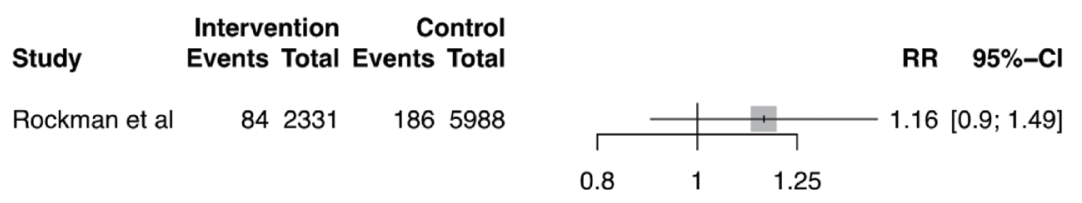

Figure S3 Meta-analysis of all publications comparing perioperative stroke rates in patients undergoing CEA with different intraoperative completion studies (ICS) to those treated with CEA without any ICS. Forest plots illustrating results of meta-analyses including all studies to compare CEA with angiography (A), IDUS (B), and flowmetry (C) to CEA without use of any ICS. CEA, carotid endarterectomy; IDUS, intraoperative duplex ultrasound; $\mathrm{RR}$, risk ratio; $\mathrm{CI}$, confidence interval.

\section{References}

67. Lohr JM, Albers B, Roat TW, et al. Effects of completion angiography on the outcome of carotid endarterectomy. Cardiovasc Surg 1995;3:299-305.

68. Branchereau A, Ede B, Magnan PE, et al. Value of angioscopy for intraoperative assessment of carotid endarterectomy. Ann Vasc Surg 1995;9 Suppl:S67-75.

69. Pross C, Shortsleeve CM, Baker JD, et al. Carotid endarterectomy with normal findings from a completion study: Is there need for early duplex scan? J Vasc Surg 2001;33:963-7.

70. Valenti D, Gaggiano A, Berardi G, et al. Intraoperative assessment of technical defects after carotid endarterectomy: a comparison between angiography and colour duplex scan. Cardiovasc Surg 2003;11:26-9.

71. Kinney EV, Seabrook GR, Kinney LY, et al. The importance of intraoperative detection of residual flow abnormalities after carotid artery endarterectomy. J Vasc Surg 1993;17:912-22.

72. Hoff C, de Gier P, Buth J. Intraoperative duplex monitoring of the carotid bifurcation for the detection of technical defects. Eur J Vasc Surg 1994;8:441-7.

73. Bandyk DF, Kaebnick HW, Adams MB, et al. Turbulence occurring after carotid bifurcation endarterectomy: a harbinger of residual and recurrent carotid stenosis. J Vasc Surg 1988;7:261-74. 